\title{
Changes in US hearing aid regulations: possible benefits and risks to Australia
}

\section{Amber Willink ${ }^{a, b, g}$, Nicholas S Reed ${ }^{b, c}$, Isabelle Boisvert ${ }^{d}$, Catherine M McMahone and Frank R Lin'f,}

${ }^{a}$ Menzies Centre for Health Policy and Economics, University of Sydney, NSW, Australia

b Cochlear Center for Hearing and Public Health, Johns Hopkins University, Baltimore, MD, US

c Department of Epidemiology, Johns Hopkins University, Baltimore, MD, US

a Sydney School of Health Sciences, University of Sydney, NSW, Australia

e HEAR Centre, Department of Linguistics, Macquarie University, Sydney, Australia

f Department of Otolaryngology, Johns Hopkins School of Medicine, Baltimore, MD, US

${ }^{g}$ Corresponding author: amber.willink@sydney.edu.au

\section{Article history}

Publication date: 2 December 2021 Citation: Willink A, Reed NS, Boisvert I, McMahon CM, Lin FR. Changes in US hearing aid regulations: possible benefits and risks to Australia. Public Health Res Pract. 2021;31(5):e3152132. https://doi. org/10.17061/phrp3152132

\section{Key points}

- Hearing care in Australia and the US is defined by high-cost devices and low adoption of hearing interventions among those with hearing loss

- Changes to US regulations that permit over-the-counter sale of hearing aids are intended to address access to, and affordability of, hearing devices

- As new direct-to-consumer devices become available in Australia, policy makers should consider how to support access to safe and effective devices, and ensure continued access to hearing care services that optimise hearing

\section{Abstract}

Objective: Hearing aids are costly for many Australians with hearing loss who are not eligible for public funding, and are not widely used. The purpose of this article is to describe a recent policy shift from the United States (US) that might improve access to hearing devices and services in Australia.

Type of program or service: In 2017, the US legislated the Over-the-Counter Hearing Aid Act of 2017, directing the Food and Drug Administration (FDA) to develop regulations for over-the-counter sale of hearing aids for mild to moderate hearing loss.

Findings: Changes in the development of hearing devices and changes to service delivery were well underway in the US prior to anticipated release of new FDA regulations, with new technology entrants in the 'hearables' market. For Australians with hearing loss not eligible for public funding, the current hearing health system is expensive and device-centred. If Australia follows suit with regulatory changes for a class of over-the-counter hearing aids, consumers are likely to benefit from access to safe and affordable devices. Additional policies to support access to hearing services are also likely to be needed.

Lessons learnt: The hearing health system in Australia will undergo tremendous change in the coming years because of the introduction of overthe-counter hearing aids in the US. For Australians to benefit, changes to regulations of devices, as well as hearing services and device provision, will be required.

\section{Hearing aid regulations in the US}

In the United States (US), almost half of adults aged 60 years and older have clinically relevant hearing loss ${ }^{1}$, and yet the use of hearing aids among older adults with hearing loss hovers between 15 and $20 \% .^{2}$ Although there 
are many reasons that older adults do not use hearing aids, cost is significant. In the US, a pair of hearing aids costs, on average, US\$4700 (A\$6540), approximately one-quarter of the annual median income of older adults. ${ }^{3,4}$ With limited insurance coverage options, most older adults bear the full cost of hearing aids out of their own pockets. ${ }^{5}$ In addition, accessing intervention for hearing loss through an audiologist, which requires prior authorisation from a specialist, is time intensive and a significant physical barrier to hearing care. Following calls from the National Academy of Medicine ${ }^{6}$, and the President's Council of Advisors on Science and Technology ${ }^{7}$ to address the accessibility and affordability challenges of hearing care for adults, the Over-theCounter Hearing Aid Act of 2017 (the Act) was introduced and passed by the US Congress. The law required the US therapeutic goods regulatory agency, the Food and Drug Administration (FDA), to define regulatory standards for over-the-counter (OTC) sale of hearing aids to address mild to moderate hearing loss by August 2020. The FDA was yet to issue these regulations as this paper was finalised, but recent US government announcements indicated that the regulations would be introduced by late 2021.8

Previous FDA regulations governing hearing aids, written in 1977, effectively require the sale of hearing aids through a licensed provider because of concerns about device safety and effectiveness. ${ }^{6}$ Although the regulator's original concerns related to the expert knowledge required to appropriately select and adjust hearing devices for individual patients, the regulations instead led to device developments that supported the work of licensed providers rather than improved usability for end users. So that licensed providers could remain up to date with technology developments, different collaborations and business models developed between manufacturers and licensed providers, resulting in a concentration of the hearing aid manufacturing market. In 2018, more than $90 \%$ of the market was controlled by six manufacturers. ${ }^{9}$

In recent years, however, substantial technology gains have been developed, which support the safe and effective use of hearing aids without the help of a licensed provider. ${ }^{10,11}$ There has also been substantial development of OTC hearing devices called personal sound amplification products (PSAPs, sometimes called assistive listening devices). These cheaper and simpler devices cannot be marketed as medical devices in the US, which means they offer no guarantee of effectiveness for treatment for hearing loss and have no safety regulation beyond electrical product safety requirements. Historically, PSAPs were devices such as wireless amplification systems for TVs, or amplifiers for hunters or bird watchers. Although these products could be recommended by a hearing healthcare professional, they were not marketed to individuals with hearing loss. Nowadays, PSAPs also include 'hearable' technologies such as wireless amplified earbuds. The previous FDA regulations limited consumer technology companies such as Apple, Samsung, and Bose, which have their own direct-to-consumer platforms, from marketing or selling these new hearable technologies to consumers to treat hearing loss. The passage of the Act aimed to bridge the gap between PSAPs and hearing aids by facilitating greater competition in the hearing aid market. It was expected that this would increase affordability and innovation, while also ensuring consumers had greater access to hearing devices specifically regulated for safety and efficacy (e.g., through setting performance criteria for amplification and maximal sound output levels).

\section{Impact of the OTC Hearing Aid Act in the US so far}

Prior to the FDA issuing new OTC hearing aid regulations, the influence of the Act and the prospect of OTC hearing aids becoming available was already having an impact on the US hearing care landscape. BOSE, a US-based predominantly consumer audio equipment manufacturer, successfully executed a clinical trial ${ }^{12}$ of a hearing product, which led to an official first-in-kind FDA designation of 'self-fitting hearing aid'. In addition, more hearables capable of high-quality amplification, including Australia's Nuheara, have entered the marketplace while major tech giants such as Apple and Google have continued to invest in hearable products. Lastly, since the passage of the Act, new acquisitions and partnerships have been made between consumer technology companies and traditional hearing aid companies. Recent examples include William Demant offering hearing aids under the Philips name and the recent acquisition of Sennheiser's Consumer Division by Sonova. Facebook and Apple have recently shown interest in developing hearing technologies and have advertised internal positions for clinical audiologists. Collectively, these actions show the beginnings of a more readily accessible hearing care system with multiple product entry points to meet all levels of the individual's needs.

This flurry of activity in anticipation of the OTC regulations also puts pressure on the hearing healthcare community to adapt their service delivery models to support this emerging marketplace. This has manifested in new hearing care initiatives such as the company Lively, which delivers an exclusively online hearing care model. More importantly, a cornerstone for a robust OTC market is the separation of licensed hearing healthcare providers from the sale of the devices. Emerging technology that is readily accessible to consumers would particularly affect the business models of hearing healthcare providers which largely rely on device sales (e.g., with rehabilitation services bundled within device provision). An OTC hearing aid market will require a fee-for-service delivery model from hearing healthcare professionals, offering counselling and rehabilitation services regardless of product purchase and at any point along an individual's hearing journey. 


\section{How might the US changes affect hearing interventions in Australia?}

One in six Australians have hearing loss, with prevalence rising substantially with age, and yet only one-quarter seek help. ${ }^{13}$ The Australian hearing health sector is a patchwork of private and public programs and payers. Public funding to provide access to hearing services and devices is available through the Hearing Services Program and the Community Services Obligation. ${ }^{14}$ Individuals eligible for public support through one of these two programs include: those aged 21 years and older if they hold, or are a dependent of someone who holds, a pensioner concession card, a Department of Veteran's Affairs Gold or White card; members of the Australian Defence Force; referrals by Disability Employment Services; Aboriginal or Torres Strait Islander adults older than 50 years or those participating in the Community Development Program; or any person under 26 years of age. The many Australians not eligible for those public programs must bear the full cost of hearing services and hearing devices, which can cost, on average, between $\mathrm{A} \$ 1400-\$ 2800$ per hearing aid..$^{15}$ Addressing the affordability of hearing services and devices is critical to improving access to hearing treatment in Australia.

The impact of the Act in Australia could be far reaching, but much will depend on whether a similar regulatory approach is taken by Australia's Therapeutic Goods Administration (TGA), which regulates the sale of hearing aids for safety, quality and performance. Although individuals in Australia will be able to purchase these new OTC hearing devices developed for the US market either online or through a local seller, without TGA approval, they will not be marketable in Australia as medical devices beneficial for mild to moderate hearing loss. According to Australia's Therapeutic Goods Advertising Code ${ }^{16}$, advertising of new OTC hearing aids cannot mention FDA endorsement. Aligning these regulations with the FDA's requirements for a separate category of hearing aids available OTC, would support individuals with hearing loss to decipher safe and effective products specifically designed for hearing loss from other unregulated OTC PSAPs, which vary greatly in quality and effectiveness. ${ }^{10}$ As awareness about the consequences of unaddressed hearing loss increases, greater support and guidance for consumers about safe and effective options will be important.

New hearing aid regulations in Australia similar to those in the US would not only affect the selling of hearing aids in Australia, but also models of care provided by hearing healthcare professionals, which are tightly bound to the sale of hearing aids. In Australia, for individuals who do not qualify for public funding of hearing care, the Medicare Benefits Schedule (MBS) does not fund services by hearing care professionals such as audiologists for the purposes of fitting and device customisation or non-device-related rehabilitation services for hearing loss. As a result, most hearing care providers bundle the costs of their services with the costs of hearing aids. Such services include hearing evaluations; medical referrals to prevent or treat complex ear conditions; functional assessment and counselling for hearing-related difficulties at home, in the workplace, or social situations; verification and adjustments of hearing devices; and recommending and implementing the use of complementary or alternative communication strategies. ${ }^{17}$ Bundling of services with devices has gradually diminished the public's valuation of these hearing care services. This is despite studies showing the benefits - for hearing outcomes ${ }^{11}$ and healthcare spending ${ }^{18}$ - of a model that supports the provision of hearing care compared with self-fitting a device alone. Even with a direct-to-consumer market, many individuals will require and benefit from hearing healthcare services and supports. ${ }^{19,20}$

In Australia, several hearing clinics are owned by hearing aid manufacturers employing hearing health professionals, and the audiology and audiometry professions are self-regulated (i.e., without governmental involvement). Eligible adults can access public funding for hearing devices through services offered by certified clinicians, regardless of the business model in which that clinician operates. In 2017, an investigation by the Australian Competition and Consumer Commission reported concerns about sales of hearing aids being driven by commissions and other incentives rather than consumer need. ${ }^{21}$

\section{Changing the structure of hearing care provision in Australia}

In 2019, the Australian Government released the 'Roadmap for hearing health', which recommended ensuring "hearing rehabilitation beyond technology is available for Australian adults who do not currently qualify for either the National Disability Insurance Scheme or the Hearing Services Program". ${ }^{22}$ The Australian Government has since committed $\$ 21$ million towards implementation of this Roadmap. However, very little in this budget announcement addresses improving access to hearing rehabilitation beyond $\$ 350000$ allocated to developing tele-audiology standards. ${ }^{23}$

However, with or without US-style OTC hearing aids reaching Australian shores, significant changes to the structure of hearing care provision in Australia are required to ensure optimal outcomes for individuals with hearing loss. This could include greater regulation and oversight of hearing providers through the National Registration and Accreditation Scheme for health practitioners, or funding hearing care services by certified providers through the MBS to disentangle hearing health advice from hearing aid sales. Without structural changes to hearing care provision in Australia, treatment of hearing loss will continue to be commercially oriented and 
governed by consumer protection laws and regulations rather than a person-centred service to improve or maintain health.

\section{Conclusion}

As the landscape of hearing aid sales changes, the model and reimbursement of hearing care in Australia needs to evolve to guarantee optimal functional hearing and communication outcomes for anyone with hearing loss. Despite the Australian Government's 2019 Roadmap for hearing health, very little is being budgeted to address improved access to hearing rehabilitation. ${ }^{23}$ As the evidence builds for the impact of hearing loss on poor health outcomes ${ }^{24,25}$ and health care utilisation ${ }^{18,26}$, the case will strengthen for facilitating and incentivising access to hearing care services through equitable programs that complement the new market for hearing devices.

\section{Acknowledgements}

The manuscript was supported by a team of expert researchers and practitioners from Johns Hopkins University, the University of Sydney and Macquarie University (Sydney) who have been closely involved with the development of the US hearing aid regulations and the design of the Roadmap for Hearing Health in Australia.

\section{Peer review and provenance}

Externally peer reviewed, invited. CM is a Guest Editor of this themed issue of Public Health Research \& Practice. She had no part in the peer-review process for this paper.

\section{Competing interests}

IB has received funding from the Cochlear-Macquarie Partnership Scheme, and has been paid expenses to attend an Audiology Australia conference as a guest speaker (2018-19). AW has received grant funding from the Johns Hopkins Cochlear Center for Hearing and Public Health. FL has received consultancy fees from Cochlear Ltd, Amplifon and Boehringer Ingleheim. NR has received funding from $\mathrm{NIH} / \mathrm{NIA}$, one-time consultancy fees from Helen of Troy and is an advisory board member to audiometry company Shoebox and Neosensory.

\section{Author contributions}

AW, CM and FL designed the manuscript. AW wrote the manuscript with contributions from NR and IB. All authors provided critcal review and input into the final manuscript.

\section{References}

1. Goman AM, Lin FR. Prevalence of hearing loss by severity in the United States. Am J Public Health. 2016;106(10):1820-2.

2. Reed NS, Garcia-Morales E, Willink A. Trends in hearing aid ownership among older adults in the United States from 2011 to 2018. JAMA Intern Med. 2021;181(3):383-5.

3. Jacobson G, Griffin S, Neuman T, Smith K. Income and assets of Medicare beneficiaries, 2016-2035. San Francisco: Kaiser Family Foundation; 2017 [cited 2021 May 21]. Available from: www.kff.org/ medicare/issue-brief/income-and-assets-of-medicarebeneficiaries-2016-2035/

4. McNeal MH. Say what? The Affordable Care Act, Medicare, and hearing aids. Harvard Journal on Legislation. 2016;53:622-70.

5. Willink A, Reed NS, Swenor B, Leinbach L, DuGoff EH, Davis K. Dental, vision, and hearing services: access, spending, and coverage for Medicare beneficiaries. Health Aff (Millwood). 2020;39(2):297-304.

6. National Academies of Sciences Engineering and Medicine. Hearing health care for adults: priorities for improving access and affordability. Washington, DC: The National Academies Press; 2016 [cited 2021 May 21]. Available from: www.ncbi.nlm.nih.gov/sites/books/ NBK367633/

7. President's Council of Advisors on Science and Technology. Aging America \& hearing loss: imperative of improved hearing technologies. Washington, DC: PCAST; 2015 [cited 2021 May 21]. Available from: obamawhitehouse.archives.gov/sites/default/files/ microsites/ostp/PCAST/PCAST\%20hearing\%20letter\%20 report.pdf

8. Medical devices; ear, nose and throat devices; establishing over-the-counter hearing aids and aligning other regulations (RIN: 0910-A121). Washington, DC: Executive office of the President; 2021 [cited 2021 Aug 25]. Available from: www.reginfo.gov/public/do/ eAgendaViewRule?publd=202104\&RIN=0910-AI21

9. Grand View Research. Hearing aids market size, share and trends by product type (behind the ear, canal), by technology type (digital, analog), by sales channel, by region, and segment fragments, 2019-2025. San Francisco: Grand View Research; 2019 [cited 2021 May 21]. Available from: www.grandviewresearch.com/ industry-analysis/hearing-aids-market

10. Reed NS, Betz J, Kendig N, Korczak M, Lin FR. Personal sound amplification products vs a conventional hearing aid for speech understanding in noise. JAMA. 2017;318(1):89-90.

11. Humes LE, Rogers SE, Quigley TM, Main AK, Kinney DL, Herring $\mathrm{C}$. The effects of service-delivery model and purchase price on hearing-aid outcomes in older adults: a randomized double-blind placebo-controlled clinical trial. Am J Audiol. 2017;26(1):53-79. 
12. Sabin AT, Van Tasell DJ, Rabinowitz B, Dhar S. Validation of a self-fitting method for over-the-counter hearing aids. Trends Hear. 2020;24:2331216519900589.

13. Hartley D, Rochtchina E, Newall P, Golding M, Mitchell P. Use of hearing aids and assistive listening devices in an older Australian population. J Am Acad Audiol. 2010;21(10):642-53.

14. Australian Government Department of Health. Am I eligible to receive fully subsidised hearing services? Canberra: Department of Health Hearing Services Program; 2021 [cited 2021 May 5]. Available from: hearingservices.gov.au/wps/portal/hso/site/eligibility/ programhelp/eligibility

15. Yong M, Willink A, McMahon C, McPherson B, Nieman CL, Reed NS, Lin FR. Access to adults' hearing aids: policies and technologies used in eight countries. Bull World Health Organ. 2019;97(10):699-710.

16. Australian Government. Therapeutic Goods Advertising Code (No.2) 2018. In: Therapeutic Goods Administration, ed. Vol 16. 5 ed. Canberra: Federal Register of Legislation; 2021 [cited 2021 Oct 12]. Available from: www.legislation.gov.au/Details/F2021C00763

17. Laplante-Lévesque A, Hickson L, Worrall L. Rehabilitation of older adults with hearing impairment: a critical review. J Aging Health. 2010;22(2):143-53.

18. Willink A, Reed NS, Lin FR. Cost-benefit analysis of hearing care services: what is it worth to Medicare? J Am Geriatr Soc. 2019;67(4):784-9.

19. Convery E, Keidser G, Seeto M, McLelland M. Evaluation of the self-fitting process with a commercially available hearing aid. J Am Acad Audiol. 2017;28(2):109-18.

20. Hogan A, Donnelly D, Ferguson M, Boisvert I, Wu E. Is the provision of rehabilitation in adult hearing services warranted? A cost benefit analysis. Disabil Rehabil. 2020:1-6.
21. Australian Competition and Consumer Commission. Issues around the sale of hearing aids: consumer and clinician perspectives. Canberra: ACCC; 2017 [cited 2021 Aug 23]. Available from: www.accc.gov.au/system/files/ Issues\%20around\%20the\%20sale\%20of\%20hearing\%20 aids\%20-\%20Consumer\%20and\%20clinical\%20 perspectives.pdf

22. Tune D, Battersby J, Brady D, Coates H, Coles T, Edman D, et al. Roadmap for hearing health. Hearing Health Sector Committee. Canberra: Australian Government Department of Health; 2019 [cited 2021 May 21]. Available from: www1.health.gov.au/internet/ main/publishing.nsf/content/CDFD1B86FA5F437CCA25 83B7000465DB/\$File/Roadmap\%20for\%20Hearing\%20 Health.pdf

23. Australian Government. Roadmap for hearing health. Canberra: Australian Government Department of Health; 2021 [cited 2021 May 21]. Available from: www.health. gov.au/sites/default/files/documents/2021/02/roadmap-forhearing-health-overarching-implementation-roadmap-forhearing-health.pdf

24. Deal JA, Reed NS, Kravetz AD, Weinreich $H$, Yeh $C$, Lin FR, Altan A. Incident hearing loss and comorbidity: a longitudinal administrative claims study. JAMA Otolaryngol Head Neck Surg. 2018;145(1):36-43.

25. Reed NS, Assi L, Horiuchi W, Hoover-Fong JE, Lin FR, Ferrante LE, et al. Medicare beneficiaries with selfreported functional hearing difficulty have unmet health care needs. Health Aff (Millwood). 2021;40(5):786-94.

26. Reed NS, Altan A, Deal JA, Yeh C, Kravetz AD, Wallhagen M, Lin FR. Trends in health care costs and utilization associated with untreated hearing loss over 10 years. JAMA Otolaryngol Head Neck Surg. $2019 ; 145(1): 27-34$

\section{Copyright: (c) (i) (5)}

(c) 2021 Willink et al. This article is licensed under the Creative Commons Attribution-NonCommercial-ShareAlike 4.0 International Licence, which allows others to redistribute, adapt and share this work non-commercially provided they attribute the work and any adapted version of it is distributed under the same Creative Commons licence terms. See: www.creativecommons.org/licenses/by-nc-sa/4.0/ 